\title{
REPRESENTASI KARAKTER TOKOH DALAM CERPEN RUSA-RUSA MASUK KACA KARYA MOSTHAMIR THALIB: PENDEKATAN SEMIOTIK CHARLES SANDERS PEIRCE
}

\author{
Tengku Muhammad Sum \\ Universitas Lancang Kuning, Pekanbaru \\ tengkumuhammadsum@gmail.com
}

\begin{abstract}
This research has been motivated by literature as reflection of reality. The story "Rusa-Rusa Masuk Kaca" is selected because the character in the story presents reality. The study of this story uses Charles Sanders Peirce's semiotic analysis. Namely sign, object, and interprentrant. Semiotic analysis is used to analyze character representation that connect literary work with reality. The method used is qualitative descriptive with a literature study of data collection techniques.
\end{abstract}

Keywords: Short Stories Rusa-Rusa Masuk Kaca, Semiotic Peirce,

Character Representation.

\section{Pendahuluan}

Karya sastra erat kaitannya dengan kehidupan nyata. Karya sastra merupakan buah pikiran dari seorang pengarang. Hal ini sesuai dengan pendapat (Wellek dan Werren, 1970:109) yang mengatakan bahwa sastra menyajikan kehidupan yang sebagian besar terdiri atas kenyataan sosial, walaupun karya sastra juga meniru alam dan dunia subjektif manusia.
Sastra menampilkan gambaran kehidupan, dan kehidupan itu sendiri adalah suatu kenyataan sosial (Damono, 1978:1). Sastra adalah sebuah media subjektif yang mencoba mengangkat persoalan-persoalan realitas yang ada di masyarakat. Oleh karena itu, karya sastra dan masyarakat terjadi hubungan yang saling mempengaruhi. Sastra meyajikan kehidupan dan kehidupan sebagian besar terdiri 
dari kenyataan sosial, walaupun karya sastra juga meniru alam dan subjektif manusia.

Karya sastra lahir di tengahtengah masyarakat sebagai hasil dari imajinasi pengarang serta refleksi terhadap gejala-gejala sosial di sekitarnya serta merta pesan-pesan yang ingin disampaikan oleh pengarang sendiri kepada pembaca, yang berupa makna yang terkandung dalam sebuah karya sastra serta makna yang di sarankan lewat cerita itu sendiri. Menurut Nurgiyantoro (2007: 321), moral merupakan makna yang terkandung dalam sebuah karya sastra dan makna yang disarankan lewat cerita. Cerita pendek atau yang sering disingkat sebagai cerpen adalah suatu bentuk prosa naratif fiktif, yang berarti rangkaian kejadian yang bersifat khayal. Cerita pendek sendiri memusatkan perhatian pada satu kejadian, mempunyai satu plot, setting yang tunggal, jumlah tokoh yang terbatas, mencakup jangka waktu yang singkat. Cerpen dapat memuat berbagai persoalan hidup. Pengarang sering sekali menjadikan cerpen sebagai media kritik. Kritik dalam sebuah karya sastra adalah merupakan bentuk kepedulian pengarang terhadap situasi kehidupan sosial masyarkat yang tidak sesuai dengan norma yang seharusnya salah satunya adalah cerpen karya Mosthamir Thalib.

$$
\text { Cerpen-cerpen karya }
$$

Mosthamir Thalib tidak dapat diragukan lagi, karya yang memiliki karakter tersendiri dan menyuguhkan karya-karya imajinatifnya kepada para pembaca. Keberadaan dan kepiawaiannya sebgai penulis kreatif menjadi pelangi dan menghiasi cakrawala kesusasteraan Riau, beliau juga penulis skenario sinetron Telatah Wak Atan (ditayangkan dua telisi lokal Pekanbaru) dan Wak Luncai (dibintangi Him Damsyik dan Bo Abo, ditanyangkan stasiun televisi Jakarta). Karya-karya beliau berupa cerpen dan puisi terhimpun dalam Titian Laut III (ontologi cerpen dan puisi Dialog Utara III (1991, DBP, 
Kuala Lumpur), Melancong Bumi Lancang Kuning (1993, Jakarta), Pertemuan Kedua (ontologi cerpen dan puisi Sijori, 1995, DBP, Kuala Lumpur) serta Tuntut Merdeka, Dewan Kemaruk, dan Telatah Wak Atan yang merupakan tiga buku kumpulan karya Mosthamir Thalib.

Penelitian ini menggunakan metode analisi deskriptif kualitatif. Adapun landasan teoritis yang digunakan adalah semiotik untuk dapat mempresentasikan karakter tokoh dalam cerpen. Dimana teori semiotik yang digunakan yakni teori semiotik Peirce yang mengatakan bahwa sesuatu itu dapat disebut sebagai tanda jika ia mewakili sesuatu yang lain.

\section{A. Semiotika Charles Sanders Peirce}

Semiotik sebagai suatu model dari ilmu pengetahuan sosial memahami dunia sebagai suatu sistem yang memiliki unit dasar yang disebut dengan 'tanda', dengan demikian semiotik mempelajari hakikat tentang keberadaan suatu tanda.

Teori segitiga makna (triangle meaning) milik Charles S. Peirce yang terdiri atas sign (tanda), object (objek), dan Interpetran (interpetran). Menurut Peirce salah satu bentuk tanda adalah kata, sedangkan objek adalah sesuatu yang dirujuk tanda, sementara interpetran adalah tanda yang ada di dalam benak seseorang tentang objek yang dirujuk sebuah tanda (Sobur, 2012).

Mode triadik Peirce sering disebut sebagai "triangel meaning semiotics" atau dikenal dengan teori segitiga makna, yang dijelaskan secara sederhana "tanda adalah sesuatu yang dikaitkan pada seseorang untuk sesuatu dalam beberapa hal atau kapsitas. Tanda menunjuk pada seseorang, yakni, menciptakan dibenak orang tersebut atau dinamakan interpren dari tanda pertama. Tanda itu menunjukkan sesuatu, yakni objeknya”. Model triadik Peirce dan konsep 
trikotominya yang terdiri atas berikut.

1. Representament / sign (tanda)

2. Object (sesuatu yang dirujuk)

3. Interpretant ("hasil" hubungan representamen dengan objek)

Salah satu bentuk tanda (sign) adalah kata. Sesuatu dapat disebut representamen (tanda) jika memenuhi dua syarat berikut: 1). Bisa dipersepsi, baik dengan panca indera maupun dengan pikiran/ perasaan. 2). Berfungsi sebagai tanda (mewakili sesuatu yang lain). Objek adalah sesuatu yang di rujuk tanda, bisa berupa materi yang tertangkap panca indera, bisa juga bersifat mental atau imajiner, sedangkan interpretan adalah tanda yang ada dalam benak seseorang tentang objek yang dirujuk sebuah tanda. Apabila ketika elemen makna itu berinteraksi dalam benak seseorang, maka muncullah makna tentang sesuatu yang diwakili oleh tanda tersebut.

\section{Metode Penelitian}

Penelitian ini menggunakan metode kulaitatif yang sifatnya deskriptif. Dengan tujuan agar dapat menjelaskan fenomena dengan sedalam-dalamnya melalui pengumpulan data dan hasil dari penelitian yang berisi analisis data yang bersifat menuturkan, memaparkan, memberikan, menganalisis, dan menafsirkan (Sototo, 1992). Penelitian ini menggunakan teknik semiotik Charles S. Peirce membahas tiga point penting yakni sign, object, interpretan sebagai segitiga makna. Teknik pengumpulan data dengan mengamati karakter/watak tokoh dalam cerpen. Penelitian ini berfokus pada dialog yang terdapat di dalam cerpen serta hasil dari analisisnya merupakan representasi karakter tokoh dalam cerpen Rusa Rusa Masuk Kaca karya Mosthamir Thalib. 


\section{Sinopsis}

Rusa-Rusa Masuk Kaca sebuah fable yang dikemas apik oleh Mosthamir Thalin dari buku kumpulan cerpen "Tuntut Merdeka”. Watak dan karakter manusia yang disimbolkan pada hewani berupa Rusa, Kerbau, Beruk, Beruang umbut, Rusruk (Rusa - Beruk) serta hewan lainnya. Para Rusa di dalam cerpen ini beragam macam rupa, bentuk dan tingkah laku. Ketika para Rusa-Rusa masuk kaca, maka mereka akan berubah wujud. Ada yang berjalan mengenggakngenggak sambil menjulurjulurkan lidahnya maka ia menjadi Beruk. Dan mana rusa yang berjalan setapak-setapak tetap akan menjadi Rusa. Lalu mana yang berjalan lurus saja lah yang pada akhirnya akan menjadi manusia. Sedangkan yang lainnya berwujud menjadi binangan yang lain sebagaimana gaya berjalan mereka masing-masing. Ada yang jadi Kuda Binal. Ada yang jadi Kucing. Ada yang jadi Ayam Kantoran yang suka bergelut dengan KudaKuda Binal terus Beruk-Beruk Nakal. Kemudian suatu ketika Rusa Jantan yang merasa di diskriminasi terhadap bininya Rusa Betina di tempat ia bekerja dan hendak menanyakan kepada atasannya atau Bos si Beruang Umbut apa lebih bininya dan apa kurang ia, sehingga Pak Beruang Umbut memberikan fasilitas yang mewah kepada bininya. Dengan kesabaran berkawankan Kerbau yang pemalas menunggu kesempatan untuk bertemu dengan pak Berunang Umbut. Sambil melihat-lihat, Rusa pun terbayang igatan-ingatan yang lalu saat ia melihat foto Rusa Masuk Kaca serta foto yang lainnya. Penantian Rusa yang begitu lama tidaklah membuahkan hasil seperti yang di harapkan, akan tetapi membuat Rusa tidak menyangka dengan apa yang ia dapati.

\section{Pembahasan}


1. Analisis Semiotika Charles S. Peirce Cerpen Rusa - Rusa Masuk Kaca

a. Sign: Kerbau

Objek: Seekor Kerbau yang bekerja di perusahaan Kicap, Kerbau pemalas, bersifat engkek, memiliki pentung di ujung depan hidungya, serta suka menerima suap / tip.

Interpretant: Manusia yang disimbolkan sebagai Kerbau berkerja sebagai asisten Bos di perusahhan Kicap yang di pimpin oleh Beruang Umbut. Kesehariannya tidur dan bermalasmalasan. Suka menerima suap/tip dari setiap oang yang hendak menemui Pak Beruang Umbut.

b. Sign: Rusa Jantan

Objek: Seekor Rusa Jantan sederhana yang bekerja di Pabrik Kicap, polos, jujur, memiliki sifat mengalah, selalu didiskriminasi dan tertindas, memiliki tanduk yang bagus,

Interpretant: Manusia yang disimbolkan sebagai Rusa Jantan bekerja di Perusahaan Kicap pada bagian produksi kicap. Namun tanpa disadari bahwa keluguan dan kerendahan hatinya sering membuat ia terintimidasi di perusaan tersebut.

c. Sign: Beruk

Objek: Sifatnya yang buruk, menghalalkan segala macam cara, licik, pencari muka, penuh tipu muslihat, memaksakan kehendak.

Interprent: Manusia yang disimbolkan sebagai Beruk dengan sifat, karakter serta cerminan sifat buruk manusia. Bersifat licik dan suka menghalalkan segala cara.

\section{d. Sign: Pak Beruang Umbut}

Objek: Pengusaha

Perusahaan Kicap, pengusaha sukses, rakus. memaksakan kehendak.

Interpretant: Manusia yang disimbolkan sebagai Beruang Umbut. Pengusaha sukses yang dengan kedudukannya dapat melakukan apa saja dan 
mendapatkan apa saja yang diinginkannya.

e. Sign: Bini Rusa Jantan/Rusruk (Rusa-Beruk)

Objek: Nakal, binal.

Interpretant: Manusia yang disimbolkan sebagai Rusruk dengan sifatnya seperti perempuan nakal, demi mendapatkan jabatan, posisi serta segala hal yang diinginkan, terutama hal duniawai.

\section{Pembahasan Representasi Karakter Tokoh Cerpen Rusa-Rusa Masuk Kaca}

$\begin{array}{lr}\text { Kerbau } & \text { yang } \\ \text { menggambarkan } & \text { karakter dan } \\ \text { watak manusia disimbolkan } & \text { de } \\ \text { sebagai Manusia pemalas }\end{array}$

"Ngh...Ngh... Dia masih ada tam... Tunggu saja..." sahut Kerbau ini lagi sambil mengelap air liur yang meleleh dari lubang hidungnya. Kerbau ini masih saja tanpa mau membuka mata sedikit pun. Dan terus kembali dengan dengkurannya. (Hal: 2)

Berdasarkan kutipan di atas representasi karakter penokohan yang penulis dapat dari manusia pemalas yang disimbolkan sebagai kerbau adalah karakter manusia yang kita temukan dalam kehidupan sehari-hari. Manusia yang hanya bekerja serta bermanis muka apabila diberikan "uang pelicin" atau tip. Menginginkan kerja yang senang dan mudah. Tidak perlu ngoyo atau bahkan bersusah payah. Asal segala sesuatu nya sesuai dengan hitungan si Kerbau dan tidak merugikan dirinya. Sifat dan tingkah lakunya pun akan bergantung dari seberapa yang diberikan. Dengan arti lain kerbau digambarkan sebagai sosok manusia yang bathil, menerima segala sesuatu entah itu halal atau haram tidaklah penting baginya. Selanjutnya Rusa jantan disimbolkan sebagai Manusia jelata merupakan cerminan dari karakter manusia yang disimbolkan sebagai Rusa Jantan adalah manusia yang berjalan lurus di jalannya, teguh pendirian dengan prinsipnya, serta hanya ingin menjadi dirinya sendiri tanpa 
harus menonjolkan dirinya dengan cara yang salah. Rusa yang selalu dizalimi dan didiskriminasi di lingkungannya. Dapat kita lihat pada kutipan di bawah ini.

"Rusa Jantan ingin menghadap Pak Beruang Umbut, untuk protes. Mengapa bininya, seekor Rusa juga, yang baru masuk kerja ke perusahaan ini, gajinya lebih tinggi daripada gajinya. Padahal, sola pengalaman kerja, lebih dia. Soal keterampilan, mahir dia. Soal pendidiakan pun, tinggi dia. Tapi mengapa bininya, sampai dalam sola fasilitas pun, mendapatkan keistimewaan" (Hal: 2)

Namun jika kita menilik dengan kenyataan yang ada di zaman sekarang dengan tetap mempertahankan serta memiliki sifat yang dimilik Rusa Jantan hanya akan merugikan diri sendiri jikalau tidak bisa menjadi penjilat untuk mendapatkan posisi kerja yang diinginkan, gaji yang diidamkan, bermanis muka atau bahkan mengharuskan bermuka dua hanya agar mendapatkan apa yang diinginkan dan didambakan serta kedudukan yang tinggi. Namun kembali lagi hanya yang kuat imannya dan berjalan di jalan yang lurus serta jujur dan bertekad kuat yang akan bertahan pada keteguhan prinsipnya tetap menjadi rusa atau manusia seutuhnya dan tidak terpengaruh akan nikmatnya duniawi dengan cara-cara yang seperti itu. Sekanjutnya Beruk yang disimbolkan sebagai Manusia yang senang melakukan pekerjaan haram

" Hidup zaman sekarang harus berani melakukan pekerjaan haram.kalau tidak, lambat maju. Sebab barang dan pekerjaan baram itu ada disetiap pelosok dunia, sedangkan pekerjaan halal itu, hanya ada di tempat-tempat tertentu di zaman sekarang ini.." kata Beruk pada suatu hari. (Hal:8)

Dapat kita lihat dari kutipan di atas bahwa segala cerminan sifat buruk yang dimiliki manusia digambarkan atau disimbolkan sebagai Beruk. Beruk suka melakukan kerjaan haram hanya 
untuk mencapai kesuksesan dan ketenaran, menghalalkan segala cara untuk mendapatkan apa yang beruk kehendaki tanpa memikirkan perasaan makhluk lainnya. Apakah itu akan menyakitkan bagi makhluk lain atau bahkan sangat merugikan. Inilah manusia yang suka menghalalkan segala cara untuk mencapai tujuannya disimbolkan sebagai beruk. Sebagaimana sifat alamiah beruk sendiri yakni selain lincah dan lihai, beruk juga serba bisa. Beruk yang disimbolkan sebagai manusia bisa merayap, bisa hidup di darat dan laut, pandai memanjat serta meloncat-loncat, bahkan kini beruk bisa terbang di udara dari dahan satu ke dalan yang lain serta beruk yang penuh tipu muslihat. Dan dapat di jumpai juga sifat manusia yang suka dan hobi berbicara cabul serta menonton yang cabul-cabul dengan lawan jenisnya tanpa membatasi hubungan pertemanan antar lawan jenis, seperti sudah tidak adanya keterbatasan dalam perihal pergaulan antar lawan jenis.
Yang punya bini seakan lupa telah bebini. Dan yang belaki seakan lupa telah belaki. Ini yang sangat sering sekali kita lihat dalam kehidupan jaman sekarang yakni perselingkuhan, bahkan sampai kepada perzinahan. Sudah tidak lagi memiliki dan menjungjung marwah serta rasa malu di antara mereka. Milik orang lain seakan menjadi miliknya. Akan tetapi sebaliknya, miliknya tidak boleh menjadi milik orang lain. Sangat jelas sekali dimasa kini kita dapat menemuai manunia-manusia yang menjelma sebagai beruk di jaman sekarang.

$$
\text { Selanjutnya Pemimpin }
$$

Bathil disimbolkan sebagai Pak Beruang Umbut. Digambarkan sebagai pemimpin yang bathil maksudnya pemimpin yang menggunakan kekuasaannya untuk mendapatkan apa yang ia mau dan apa yang ingin ia dapatkan. Tidak peduli apakah itu akan menghancurkan hubungan salah seorang dengan yang lain, yang 
terpenting dengan kekuasaannya ia bisa mendapatkan segala hal yang ia inginkan. Bahkan istri orang pun bisa menjadi miliknya dengan uang dan kekuasaannya. Kita dapat melihat manusia dengan karakter demikan, atas kedudukan dan kekuasaannya, suka semena-mena dengan manusia di bawahnya. Dengan kekuasaan dan kedudukannya seakan ia dapat membeli harga diri serta status seseorang. Dapat dilihat dari kutipan di bawah ini.

“ Di sini di bekerja membuat Kicap juga" jelas Berungan Umbut

"Tetapi mengapa di ruang Bos ini?"

"Di sini khusus membuat Kicap putih,"

Rusa Jantan tercengang. Bingung. "Setahu aku, kita tak pernah memproduksi Kicap putih."

"Memang. Tak setahu karyawan. Kita sudah lama memproduksinya, hanya dipasarkan di kalangan tertentu."

Rusa Jantan masih terbingung-bingung, "Tetapi lagi, sahut aku pula kami bangsa Rusa, termasuk biniku, tak bisa membuat selain Kicap hitam..."

Pak Beruang Umbut tertawa terkikik-kiki. "Memang benar, bangsa Rusa itu hanya bisa mengerjakan Kicap hitam. Tetapi bini-bininya itu, sebagian bukan bangsa Rusa."

"Memangnya bangsa apa dia kalau bukan Rusa?" "Rusuk!" teriak Beruang Umbut, tiba-tiba. (Hal: 21)

Hal ini tidak akan berlaku bagi mereka yang memiliki keimanan akan sangat sadar bahwa semua yang telah di titipkan di dunia ini hanya bersifat sementara. Kesenangan duniawi jika diikutkan takkan ada habisnya.

Selanjutnya Bini Rusa Jantan yang berubah menjadi Rusruk disimbolkan sebagai sosok perempuan yang berperangai nakal.

Bini Rusa Jantan tak menjawab. Cuma tersenyum saja, tersingaisingai. Tersungging tidak, tersengging tidak, tertawa pun.

Bini Rusa Jantan itu berbalik arah. Masih tersingai-singai, kembali 
mendekati Beruang Umbut dan Rusa Jantan.

"Coba singkap tandukmu yang bercabang-cabang molek itu!" perintah Beruang Umbut.

Masih wajah tersingaisingai, bini Rusa Jantan yang baru diketahui oleh Rusa Jantan berganti nama Rusruk, mengangkat tanduknya, bagaikan seorang gadis anak manusia mengangkat selendangnya. (Hal: 21-22)

Kutipan di atas merupakan cerminan dari perempuanperempuan yang lupa akan marwahnya. Dan melakukan hal apa saja agar mendapatkan posisi yang bagus, hidup yang enak, berlebih-lebih tidak kekurangan apapun. Sampai harus "bermain" atau menuruti semua perintah atasan pun ia lakukan demi posisi yang lebih baik, sampai melupakan status rusruk ini sendiri. Tidak lagi melihat apakah itu halal atau haram, semua dipukul rata dimata rusruk. Dengan alasan kapan akan menikamti dan meresakan nikmat duniawi jikalau hidup dijalani seperti Rusa Jantan.

\section{Simpulan}

Berdasarkan hasil analisis model semiotika Charles Sanders Peirce terhadapat representasi karakter tokoh dalam cerpen RusaRusa Masuk Kaca maka dapat ditarik kesimpulan bahwa ada macam banyak perwujudan manusia di zaman sekarang. Cerpen di atas mengangkat permasalahan yang sudah jelas terlihat di depan mata, bahkan sudah jadi hal biasa jika dalam mendapatkan posisi dan kedudukan jika tidak menjadi penjilat dan bersilat lidah dengan sedikit tipu muslihat selamanya hanya akan menjadi Rusa Jantan. Namun jika sebaliknya akan menjadi Beruk, Rusruk, dan perubahan wujud hewan lainnya. Karakter-karakter kebodohan, dan gambaran rendahnya manusia daripada binatang. Di jaman sekarang banyak manusia memakan dan melakukan yang haram, sudah tidak dapat di bedakan lagi mana halal mana 
haram, mana yang boleh mana yang tidak boleh, mana yang hak sendiri mana yang hak orang lain. Semua tercampur aduk dengan tujuan kenikmatan duniawi. Cerpen karya Morthamir Thalib membuka mata para pembaca akan kenyataan yang ada di sekitar kita tentang keadilan dan ketidakadilan, kebenaran dan ketidakbenaran, serta kemanusian dan kebinatangan.

\section{DAFTAR PUSTAKA}

Sobur, Alex. 2012. Analisis Teks Media: Suatu Pengantar Amalisis Wacana, Analisi Semiotika, dan Analisis Framing. Bandung: Remaja Rosdakarya.

Ali, Muhammad. 1986. Sastra dan Manusia. Surabaya:

PT. Bina

Indra Karya Surabaya.

Danesi, Marcel. 2010. Pesan, Tanda, dan Makna: Buku
Teks Dasar Mengenai Semiotik dan Teori Komunikasi. Yogyakarta: Jalasutra.

Damono, Sapardi Djoko. 1978. Sosiologi Sastra: Sebuah Pengantar Ringkah. Jakarta: Pusat Pembinaan dan Pengembangan Budaya.

---------. 1983. Kesusastraan Indonesia Modern. Jakarta: Gramedia.

Nurgiyantoro, Burhan. 2010. Teori Pengkajian Fiksi. Yogyakarta: Gadjah Mada University Press.

Ratna, Nyoman Kutha. 2013. Teori, Metode, dan Teknik Penelitian Sastra. Yogyakarta: Pustaka Pelajar.

Satoto, Soediro (Eds.). 2000. Sastra: Ideologi, poliyik dan Kekuasaan. Surakarta: Muhammadiyah University Press.

Todorov, Tzevtan. 1985. Tata Sastra. Jakarta: Djambatan. 